\title{
ЭКОНОМИЧЕСКОЕ УГОЛОВНОЕ ПРАВО: ЕВРОПЕЙСКИЕ И РОССИЙСКИЕ ПЕРСПЕКТИВЫ
}

Аннотация: На факультете права Национального исследовательского университета «Высшая школа экономики» 17 октября 2014 г. был проведен международный круглый стол «Экономическое уголовное право: европейские и российские перспективы» в память о докторе юридических наук, профессоре, заслуженном деятеле науки РФ Альфреде Эрнестовиче Жалинском. Был представлен первый том его избранных трудов, посвященный криминологии, а также сделаны доклады по теме круглого стола. В мероприятии приняли участие ведущие российские и зарубежные ученые. Приводятся основные позици докладов участников, в том числе о необходимости обособления самостоятельной подотрасли экономического уголовного права. Оцениваются изменения, внесенные в УК РФ. Участники круглого стола пришли к выводу о необходимости избегать внесения необдуманных изменений в уголовный закон, а также о налаживании сотрудничества России и других стран. Был отмечен вклад А.Э. Жалинского в сотрудничество с Германией. Особое внимание должно уделяться участию России в международных организачиях, использованию возможностей международного права.

Ключевые слова: Экономическое уголовное право, уголовное право, международное право, международное сотрудничество, экономические преступления, мотенничество, незаконное предпринимательство, отмывание денег, ответственность юридических лии, уголовная политика.

Abstract: On October 17, 2014 the Law Faculty of the National Research University "Higher School of Economics" hosted an international roundtable event called "Economic Criminal Law": Europe's and Russia's perspectives" in honor of the Doctor of Juridical Sciences, Professor, and Merited Scientist of the Russian Federation Alfred E. Zhalinsky. The proceedings included presentation of the first volume of his selected works dedicated to criminology, as well as reports on the topic of the roundtable. Some of leading Russian and foreign scientist have taken part in this event. The article offers the Key positions of the reports made by the participants, including those on the need to form a separate independent sub-branch of Economic Criminal Law. An evaluation is given to the changes made to the Criminal Code of the Russian Federation. The participants of the roundtable have reaffirmed the need for the more thought-out changes in criminal law, as well as the strengthening of the cooperation between Russian and other countries. The contribution of Alfred E. Zhalinsky into the cooperation with Germany has also been highlighted. A special attention should be given to the participation of Russia in the international organizations and the use of the capabilities of international law.

Keywords: Economic criminal law, international law, criminal law, international cooperation, economic crimes, money laundering, Criminal law, illegal entrepreneurship, legal entities liability, criminal policy.

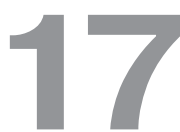

октября 2014 г. на факультете права Национального исследовательского университета «Высшая школа экономики» состоялся международный круглый стол «Экономическое уголовное право: европейские и российские перспективы», проводившийся в память о докторе юридических наук, профессоре, заслуженном деятеле науки РФ Альфреде Эрнестовиче Жалинском и приуроченный к началу выхода собрания его избранных сочинений.

В начале круглого стола была проведена презентация книги: Жалинский А.Э. Избранные труды: в 4-х т.
Т. 1. Криминология / Отв. ред. О.Л. Дубовик. - М.: Изд. дом Высшей школы экономики, 2014. - 698 с.

Вступительное слово сказал д.ю.н., профессор, заведующий кафедрой уголовного права НИУ ВШЭ Г.А. Есаков. Он поблагодарил присутствующих за участие в работе круглого стола. С презентацией книги выступила д.ю.н., профессор, главный научный сотрудник ИГП РАН О.Л. Дубовик. Она произнесла слова благодарности всем присутствующим на круглом столе, а также Высшей школе экономики, приступившей к изданию избранных трудов А.Э. Жалинского. Первый 


\section{Право и политика $2(182) \cdot 2015$}

том указанных трудов посвящен криминологии, второй - российскому уголовному праву, третий - уголовной политологии, сравнительному и международному уголовному праву и четвертый - правовому мышлению и профессиональной деятельности юриста, науковедческим проблемам уголовного права.

О.Л. Дубовик коротко осветила ход работы по отбору сочинений для первого тома, выразив признательность составителям книги, оказавшим ей помощь в обработке большого объема опубликованного и неопубликованного материала - А.А. Попову, К.А. Барышевой, И.И. Нагорной. Структура тома предопределена развитием творческой мысли А.Э. Жалинского. О.Л. Дубовик подчеркнула неизменность стиля его письма на протяжении многих лет. Отдельная благодарность была высказана издателям работ А.Э. Жалинского - О.К. Павловой, Л.В. Рожникову, А.Л. Соловьеву, Л.В. Ильиной и другим, а также его соавторам - профессорам М.М. Бабаеву и А.В. Наумову и многим другим. Особую признательность О.Л. Дубовик выразила ректору НИУ ВШЭ Я.И. Кузьминову.

Далее, слово было предоставлено профессору Бременского университета (ФРГ) Герду Винтеру. Г. Винтер поблагодарил за возможность выступить на круглом столе. Он выразил сожаление относительно нынешней ситуации, при которой вновь возникли барьеры между Востоком и Западом. Г. Винтер подчеркнул, что в свое время удалось преодолеть препятствия между социализмом и капитализмом, и выразил надежду на продолжение сотрудничества Востока и Запада. По его мнению, обе стороны должны сформулировать новую общую цель. Существует иной враг - иррациональность, в том числе религиозный фундаментализм. Второй враг, который ее поддерживает - глобальный финансовый капитал.

Сегодня очень важно, чтобы находились люди, которые создают мосты между Востоком и Западом, чтобы защищаться от общих врагов. А.Э. Жалинский строил такие мосты. Он был энциклопедически образованным человеком. Помимо знаний в области уголовного, конституционного и других отраслей права, он обладал социологическими, историческими и политическими познаниями. Особое место ему принадлежит как строителю моста между Россией и Германией в области права. В этом плане А.Э. Жалинский особенно известен благодаря книгам «Введение в немецкое право» (М., 2001; в соавт. c А.А. Рёрихт) и «Современное немецкое уголовное право» (М., 2006). Г. Винтер отметил, что подготовка и написание таких книг требует глубокого проникновения в обе культуры, потому что, не проникнув в суть другой правовой культуры, провести настоящее сравнительно-правовое исследование невозможно.

Над книгой «Современное немецкое уголовное право» А.Э. Жалинский работал за счет семейных средств. Профессор Г. Винтер предпринял шаги, чтобы помочь с финансированием покупки необходимой литературы в Германии. Но проект А.Э. Жалинского не соответствовал программам грантов и заявок, так как различные немецкие союзы и общества обычно поддерживают только очень большие и очень дорогие проекты. Индивидуальные проекты финансируются лишь в обратном направлении: гражданам Германии предоставляется возможность экспортировать немецкое право в другие страны. В конце концов, по просьбе Г. Винтера министр юстиции Германии выделил 5 тыс. марок на издание книги в России. Л.В. Рожников напечатал ее в издательстве «Проспект».

Г. Винтер полагает, что по-настоящему гениальные произведения создаются, только когда их автор нуждается. Он отметил, что эти две работы по немецкому праву пригодились многим. И возможно, что даже преступники почувствовали себе влияние этих книг, так как российские судьи получили возможность ориентироваться в своей работе на очень качественную догматику.

Также Г. Винтер высказал теплые слова об О.Л. Дубовик, подчеркнув, что она является крупным специалистом в области экологического права и строительницей «зеленого» моста между Россией и Германией.

Далее выступил член редакционного совета первого тома, д.ю.н., профессор кафедры конституционного и муниципального права НИУ ВШЭ М.А. Краснов. Он подчеркнул серьезное отношение А.Э. Жалинского к своим трудам, его глубокий подход к научной работе.

Д.ю.н., профессор, главный научный сотрудник ВНИИ МВД РФ М.М. Бабаев отметил, что А.Э. Жалинский был требователен к себе самому и своим работам. Он был выдающимся ученым, мыслителем, чьи труды не похожи на другие.

Переходя к содержательной части круглого стола, Г.А. Есаков выступил со вступительным докладом об экономическом уголовном праве, его природе, содержании и перспективах развития. Он обратил внимание на то, что данный термин часто встречается в науке уголовного права, однако ряд исследователей относится к нему негативно, называя несколько причин: 1) термин является иноязычным, представляет собой кальку с 
немецкого и французского «уголовно-хозяйственного права»; 2) его выделение размывает единство отрасли. Также существуют споры о том, что следует включать в данную область знаний.

А.Э. Жалинский придерживался мнения о том, что экономическое уголовное право существует в качестве подотрасли уголовного права. О подотраслях уголовного право сегодня говорится очень мало, хотя они долго существовали на протяжении истории отечественного уголовного права. До 1917 г. был массив уголовного права, наряду с которым существовали его подотрасли, в частности, военное уголовное право.

Исходя из современных реалий, можно вернуться к постановке вопроса о существовании подотраслей уголовного права. По мнению Г.А. Есакова, следует говорить о постепенном обособлении как минимум трех подотраслей уголовного права: экономического, военного и международно-уголовного права.

Существуют несколько критериев их выделения два содержательных и один несодержательный.

К содержательным критериям относятся: 1) наличие специфических норм Общей части УК РФ; 2) существование особых уголовно-правовых запретов в Особенной части УК РФ.

Военное уголовное право отличается специфическим описанием субъектов преступлений, соучастия, видов наказания, его назначения, исполнения, и др. Международно-уголовное право также имеет свои особенности, касающиеся, в частности, действия закона в пространстве, пределов ответственности субъекта. Экономическое уголовное право отличается особым описанием субъектов преступления, их вины, криминообразующих признаков.

Каждой подотрасли соответствует специфический блок преступлений.

Несодержательный критерий, который часто встречается в компаративистике, - это признание подотрасли со стороны науки. В связи с этим можно выделить группу специалистов, которые пишут преимущественно по экономическому уголовном праву.

Г.А. Есаков обосновал специфику экономического уголовного права, которая проявляется в следующем:

1. Критерии криминализации, неспецифичные для других глав УК РФ - крупный размер, крупный ущерб. Экономические преступления тесно связаны с примыкающей областью - административными правонарушениями.

2. Описание субъекта преступления, не свойственное для иных глав УК РФ. Экономические преступления чаще всего совершаются в процессе деятельности юридического лица. Уголовное право неизбежно сталкивается с необходимостью определить субъекта, который будет привлечен к ответственности. В связи с этим существуют теории работника, руководителя, прав и обязанностей.

3. Субъективная сторона состава преступления. По многим составам главы 22 необходим только прямой умысел ввиду специфики криминообразующих признаков.

4. Уголовно-правовая значимость юридической ошибки, с чем постоянно сталкивается судебная практика.

5. Преюдициальная значимость решений судов по гражданским делам.

Эти вопросы важны и для других глав, но наиболее рельефно они обсуждаются именно в связи с экономическим уголовным правом.

Г.А. Есаков подчеркнул, что для признания существования подотрасли не нужна декодификация уголовного закона. Тем не менее следует признать, что некоторые преступления требуют специфических уголовно-правовых конструктов. Исследователи смогут ограничиться в своей работе конкретным блоком преступлений, не задумываясь о том, насколько результаты их исследований применимы ко всем преступлениям. На современном этапе развития уголовного права, увеличение знаний влечет автономное существование отдельных его блоков.

Отвечая на вопросы присутствующих, Г.А. Есаков отметил, что названные подотрасли рассматриваются не только на уровне науки, но и на уровне учебной дисциплины, о чем свидетельствует разработка на факультете права НИУ ВШЭ магистерской программы по экономическому уголовному праву.

Г.А. Есаков обратил внимание на то, что в правовой науке не существует единого понимания подотраслей и институтов. Подотрасль - это не механическое объединение институтов, это симбиоз специфических институтов Общей части с нормами Особенной части. Нормативного оформления статуса подотрасли не требуется, скорее, это должно быть сделано на теоретическом уровне.

Необходимо определить целевое предназначение уголовного закона, т.е. каким образом уголовное право может влиять на экономику. Это вопрос о критериях криминализации отклоняющегося экономического поведения. Что-то должно защищаться гражданским правом, что-то уголовным. Обособив подотрасль экономического уголовного права, мы сможем сфор- 


\section{Право и политика 2 (182) 2015}

мулировать в хаосе норм ясные и понятные правила привлечения к уголовной ответственности, чтобы избежать необоснованного применения уголовного закона.

Д.ю.н., профессор кафедры уголовного права и криминологии Российской правовой академии Минюста РФ А.В. Наумов посвятил свой доклад уголовной ответственности в сфере борьбы с экономической преступностью в свете событий на Украине. Он подчеркнул: как бы мы ни относились к этим событиям, вопросы уголовной политики невозможно рассматривать без их учета. А.В. Наумов разделил применяемые санкции на два вида: экономические и политические.

В России наблюдалось легкомысленное отношение к экономическим санкциям, указывалось, что от них больше пострадает другая сторона. По мнению А.В. Наумова, последнее нас должно интересовать меньше всего. Введение санкций наложилось на трудный период в экономике. Минэкономразвития России еще раньше дал неутешительный прогноз экономического развития. Уголовная политика должна ответить на вопрос, как нам минимизировать влияние этих негативных факторов.

А.В. Наумов обратил внимание на плохое знание о работах в рассматриваемой сфере. В частности, практически отсутствуют ссылки на международную коллективную монографию «Верховенство права как фактор экономики» (М., 2013), соавтором которой являлся А.Э. Жалинский.

Средства массовой информации допускают нападки на либеральную экономику. Очевидно, что без расширения малого и среднего бизнеса невозможно поднять экономику. О такой поддержке для территории Крыма было заявлено на самом высоком уровне. Остается вопрос о территории всей России.

А.В. Наумов подчеркнул, что давно борется с тем, что слова «предприниматель» и «бизнес» ассоциируются с преступностью. Законодательство развитых стран не знает понятия «незаконное предпринимательство». Ответственность там наступает за тот ущерб, который причиняется экономике. Что изменится, если убрать эту статью из УК РФ? Ничего, так как останутся налоговые преступления, причинение вреда при оказании услуг и т.д. Пробелов в законодательстве нет, а клеймо существует. Ссылки на гражданское право в этом отношении неуместны, так как оно регулирует предпринимательскую деятельность с иных позиций.

Кроме того, А.В. Наумов указал на недопустимость подсчета полученного в результате незаконного предпринимательства дохода в крупном размере без учета произведенных затрат.
Говоря о политических санкциях, А.В. Наумов обратил внимание на призывы уходить из международных организаций, в том числе из Европейского суда по правам человека, по причине неэффективности международного права, и на предложения о возврате смертной казни. Эти призывы неверны. А.В. Наумов убежден: за международное право нужно бороться. Это инструмент, который надо использовать.

Россия подписала Римский статут, но не ратифицировала его, во многом под влиянием США, которые отозвали свою подпись. События на Украине подпадают под преступления, прописанные в Римском статуте, и сегодня его необходимо ратифицировать. Следственный комитет РФ много делает по расследованию преступлений, совершенных на территории Украины. Эти материалы необходимо представить в Международный уголовный суд.

Сегодня обсуждается тема антиамериканизма и антиевропеизма. Этого нельзя допускать. Даже И.В. Сталин в начале Великой Отечественной войны сказал, что Гитлер приходит и уходит, а немецкий народ остается. Президент США - это еще не вся Америка. Три экс-посла США в России высказали общее мнение о несогласии с оценкой Правительством США событий на Украине. Многие немецкие политики высказались так же. Надо вести правильную информационную политику. США - это прежде всего великая культура, с которой необходимо сотрудничать.

Доктор права, исследователь Александровского института университета Хельсинки, инспектор Центральной криминальной полиции Финляндии Ярмо Койстинен выступил с докладом о совмещении национальных законодательств при сотрудничестве в борьбе с российско-финскими экономическими преступлениями. Под последними в докладе понимались деяния, совершенные и на территории России, и на территории Финляндии.

В качестве примера был рассмотрен состав отмывания денег. Я. Койстинен подчеркнул значение Соглашения о сотрудничестве в борьбе с преступностью между правительствами России и Финляндии 1994 г. и Европейской конвенции о взаимной правовой помощи по уголовный делам 1959 г., которые создали формальные предпосылки для сотрудничества двух стран. На практике Соглашение 1994 г. применяется на стадии оперативно-розыскной деятельности. Когда расследование начато, действует Европейская конвенция 1959 г. 
Национальное законодательство также существенно влияет на сотрудничество. Согласно результатам проведенного интервью с сотрудниками полиции Финляндии, работавшими с российскими правоохранительными органами, особенно такое влияние ощущается в связи с расхождением:

- продолжительности и содержания доследственной проверки;

- момента возбуждения уголовного дела и начала предварительного расследования;

- правового положения участников предварительного расследования;

- правового характера документа завершения предварительного расследования.

В Финляндии не существует особой стадии возбуждения уголовного дела, предварительное расследование начинается, когда есть основание полагать, что преступление совершено. В России уголовное дело возбуждается, когда есть достаточные данные, указывающие на признаки преступления. Таким образом, в России требования выше.

Статус подозреваемого в Финляндии, в отличие от России, сохраняется до конца предварительного расследования. Из-за этого могут возникнуть проблемы с исполнением запроса о допросе подозреваемого.

Способами отмывания денег по финскому законодательству являются принятие, использование, конвертирование, хранение и передача имущества, добытого преступным путем. Согласно Закону о предотвращении и раскрытии отмывания денег и финансирования терроризма 18.7.2008/503 банки и иные кредитные организации обязаны идентифицировать личность клиента при размере операции не менее 15 тыс. Евро, в Законе указаны и иные основания для проверки.

На практике возникают следующие вопросы: может ли финский правоохранительный орган начать предварительное расследование, пока не установлены все признаки преступления по российскому закону? Для установления преступного происхождения денег требуется ли приговор суда или решение о привлечении к административной ответственности? Проблема заключается в том, что в Финляндии нет категории административных правонарушений.

Д.ю.н., профессор кафедры уголовного права и криминологии МГУ им. М.В. Ломоносова A.B. Серебренникова провела анализ уголовной ответственности за мошенничество по УК Германии. По ее мнению, введение шести новых составов мошенничества в УК РФ по немецкому образцу неудачно.

Хотя статья о мошенничестве всегда применялась на практике, по мнению депутатов Государственной Думы РФ, она способствовала реализации коррупционных схем, участию в рейдерских захватах. Новые статьи были призваны снизить количество ошибок и злоупотреблений со стороны правоприменителя. Однако эффект применения новых норм оказался не такой, как ожидалось.

В Германии не один десяток лет существуют различные нормы о мошенничестве, в том числе компьютерном. Для примера в 2013 г. было зарегистрировано 23042 деяния по статье «Компьютерное мошенничество», по сравнению с 2012 г. их количество снизилось на 6\%. Однако раскрыт всего $31 \%$ преступлений. Зачем же было заимствовать немецкий опыт?

А.В. Серебренникова отметила, что в Германии существует совершенно другая система имущественных преступлений. Доктрина и законодатель структурирует их следующим образом: преступления против собственности и иных имущественных благ и против имущества в целом. Раздел УК Германии о мошенничестве и преступном злоупотреблении доверием включает в себя, в частности, мошенничество, компьютерное мошенничество, злоупотребление страхованием. Статьи содержат обширные описательные диспозиции. Предметом посягательства является имущество потерпевшего в целом, совокупность всех экономических благ лица.

Д.ю.н, профессор кафедры уголовного права МГЮА им. О.Е. Кутафина Л.В. Иногамова-Хегай в своем докладе рассмотрела динамику развития законодательства в сфере противодействия экономическим преступлениям. Проанализировав поправки в главу 22 УК РФ за последние годы, она указала на одну позитивную норму, которая пошла на благо борьбе с преступностью. А именно упразднение ст. 173 «Лжепредпринимательство», которая фактически не применялась. Остальные изменения привносят рассогласованность и мешают работе правоприменителя. По сути, введено множество статей, которые кусочками закрепили положения ст. 173 УК РФ.

Внесенные нормы о мошенничестве привели к разнобою в правоприменении, возникли вопросы об обратной силе уголовного закона.

Одна из специальных норм - мошенничество в сфере социальных выплат. Какую норму применить, 


\section{Право и политика 2 (182) 2015}

если деяние о подделке документов в сфере социальных выплат совершено в крупном размере?

Л.В. Иногамова-Хегай привела пример: преступление фактически прекращено в феврале 2014 г. В марте 2011 г. был достигнут крупный размер. 7 декабря 2011 г. была дополнена ст. 159 основным наказанием в виде принудительных работ. 29 ноября 2012 г. введены специальные виды мошенничества.

Л.В. Иногамова-Хегай предложила применять закон по юридическому окончанию преступления, исходя из принципа толкования сомнений в пользу потерпевшего.

Юридическое окончание мошенничества - март 2011 г. Закон от 7 декабря 2011 г. более мягкий и имеет обратную силу.

Далее, существует конкуренция общей и специальной нормы. Более жесткая санкция в общей норме о мошенничестве. Следовательно, применяется ст. 159.4 УК РФ.

На сравнение норм ушло много времени. При опросе практических работников не все правильно определили применимый закон. Не следует вносить постоянные изменении в УК РФ, чтобы норма была понятна не только ученым, но и правоприменителю.

К.ю.н., доцент кафедры уголовного права НИУ ВШЭ Р.О. Долотов обратил внимание на существование квазиуголовной ответственности юридических лиц. Он подчеркнул, что вопрос об уголовной ответственности юридических лиц завязан на экономике, и ее введение вызовет колоссальный эффект. В настоящее время это наиболее твердый камень преткновения. В первоначальных проектах УК РФ предусматривалась такая ответственность, но тогда от нее отказались. В странах СНГ только Молдова сразу ввела подобную ответственность, затем ее примеру последовали Грузия, Азербайджан и Украина.

В России введение уголовной ответственности юридических лиц активно лоббируется Следственный комитетом РФ. В одном из законопроектов было предложено все такие преступления отнести к его подследственности.

В сентябре 2014 г. председателем Совета Федерации был внесен законопроект о дополнении норм о конфискации. Было предложено распространить их на «других лиц», в случаях предусмотренных Особенной частью УК РФ. Одновременно предлагалось дополнить ст. 199 УК РФ примечанием о введении конфискации в отношении имущества юридических лиц, если учредитель (участники) либо исполнительные органы знали или могли знать об использовании возможностей либо имущества юридического лица для совершения преступления.

Такое поведение, несомненно, общественно опасно. Например, в США банк Credit Swisse был оштрафован на 2,5\% млрд долл. за помощь в уклонении от уплаты налогов. В России размах такой деятельность также велик.

Несмотря на это, предложенный подход опасен. Он по сути означает введение квазиуголовной ответственности. При этом в главе 4 УК РФ ничего не говорится о юридических лицах. Системное толкование не позволяет распространить уголовный закон на юридических лиц. Таким образом, частный вопрос решается казуистическим способом, что создаст прецедент для такого же решения иных вопросов. Подобное было с административной преюдицией. Сначала были внесены поправки в ст. 178 УК РФ, затем и в другие статьи. Сегодня каждый второй-третий законопроект об изменении УК РФ содержит преюдицию.

Есть и чисто юридико-технические замечания по законопроекту. Какое именно имущество имеется в виду? Что значит «могли знать»? По сути, это неосторожное пособничество, которое не является преступлением. Как быть с объективным вменением? Почему ставится знак равенства между умышленным и неосторожным деянием?

Попытки введения квазуголовной ответственности не могут быть оформлены правильно, пока мы в системной виде не пропишем их в Общей части УК РФ.

Р.О. Долотов подчеркнул, что существует устоявшаяся практика введения под видом административной ответственности по сути уголовных наказаний, например штрафа в размере до 60 млн. руб. Как пишет профессор МГУ Л.В. Головко, это по сути уголовная ответственность юридических лиц. Разделение на административную и уголовную ответственность искусственное. Де факто привлекая лиц к уголовной ответственности, их лишают процессуальных гарантий по УПК РФ. Эту проблему можно решить либо введением уголовных проступков, либо отказом от административной ответственности. Или же нужно оставить все как есть, но четко разграничить уголовную и административную ответственность.

Подводя итоги круглого стола, О.Л. Дубовик сделала вывод о вечности обсуждаемых проблем. Российские специалисты способны их решить. В то же время, как правильно подчеркивали некоторые выступающие, возникают трудности в связи с неква- 
DOI: $10.7256 / 1811-9018.2015 .2 .14262$

При цитировании этой статьи сноска на dоі обязательна

Научная жизнь

лифицированным лоббируемым правотворчеством и другими факторами. Сегодня эти проблемы вышли на новый виток, есть свежие примеры новых изменений. Это свидетельствует о том, что факультет права НИУ ВШЭ справедливо уделяет внимание охране бизнеса законом. А.Э. Жалинский внес свой вклад в эту тему с разумных экономических позиций.

Постановка вопроса о подотраслях уголовного права верна. Работать над подотраслями в рамках исследований и процесса обучения намного удобнее. Академик В.Н. Кудрявцев всегда замечательно структурировал и систематизировал и отмечал, что сделать хорошую структуру и выделить новый элемент значит найти что-то новое.

О.Л. Дубовик поблагодарила докладчиков и всех участников круглого стола. Г.А. Есаков также высказал слова благодарности и пригласил участников к предоставлению материалов для издания сборника.

\section{Библиография:}

1. Жалинский А.Э. Избранные труды: в 4-х т. Т. 1. Криминология / Отв. ред. О.Л. Дубовик. - М.: Изд. дом Высшей школы экономики, 2014. - 698 с.

\section{References (transliterated):}

1. Zhalinskii A.E. Izbrannye trudy: v 4-kh t. T. 1. Kriminologiya / Otv. red. O.L. Dubovik. - M.: Izd. dom Vysshei shkoly ekonomiki, 2014. $-698 \mathrm{~s}$ 